published annually by the Human Fertilisation and Embryology Authority included rates of multiple pregnancy and birth rates according to both the woman's age and the number of embryos transferred.

Any policy allowing numerous embryos or oocytes to be replaced entails a calculated risk of multiple pregnancy. Our data support the point made by Redgment and colleagues that the principle underlying the present policy leaves room to raise the number of embryos or eggs replaced in women aged 40 and over to try to increase their pregnancy rates while keeping rates of multiple pregnancy down to what is currently acceptable in women under 40 .

CHARLOTTE FLEMING Clinical rese LISA JOELS Clinical research fellow MGR HULI

University of Bristol,

Department of Obstetrics and Gynaecology,

St Michael's Hospital

Bristol BS2 8EG

1 Redgment CJ, Al-Shawaf T, Grudzinskas JG, Craft IL. Gamete intrafallopian transfer in older women: effect of limiting intrafallopian transfer in older women: effect of limiting
number of gametes transferred. $B M F$ 1994;309:510-1. (20-27 August.)

2 Human Fertilisation and Embryology Authority. 3rd Annual report (for 1992). London: HFEA, 1994.

\section{Ulcerative colitis and Crohn's disease}

EDITOR,-Anne Ferguson's editorial on ulcerative colitis and Crohn's disease has one curious omission.' Ferguson asks, 'Why is there so little knowledge about the causes of two such serious, common, and chronic diseases-and no sign of cure?" But she does not mention that both diseases can be exacerbated by foods that are not tolerated, and she does not discuss the importance of this for the understanding of causation.

Intravenous feeding or hypoallergenic ora formulas are used to bring Crohn's disease into remission, and the two controlled trials that have examined the issue both found that food challenge followed by the avoidance of foods that were not tolerated significantly prolonged the duration of remission. ${ }^{23}$ Responses in ulcerative colitis are less consistent, but each of us knows of patients with proved ulcerative colitis in whom a projected colectomy was rendered unnecessary by a full investigation of allergy and appropriate avoidance or specific prophylaxis, or both; patients remained well for years unless they inadvertently ate one of the foods that they could not tolerate. McEwen showed that specific prophylaxis with enzyme potentiated desensitisation (without a preliminary exclusion diet) resulted in better long term outcome than placebo. ${ }^{4}$

Patients with these conditions must be closely supervised during food challenges to prevent reactions setting off a relapse. This can be achieved by adjusting their drug treatment or by curtailing symptoms by using the neutralisation technique. ${ }^{3}$

Exacerbation by certain foods (different ones for different patients) indicates an environmental element in the causation of these diseases. The prevalence of other chronic diseases in which similar exacerbations are described-eczema, asthma, and the irritable bowel syndrome-has also increased in the past 40 years. So has the prevalence of hay fever, which was first described after the start of the industrial revolution by Bostock in London in 1819; in the next nine years he heard of only 18 other cases.

The hypothesis that the increase in these diseases is due to increased chemical pollution of food, air, and water would be difficult to prove or disprove but should be urgently addressed because of the seriousness of future prospects if it was true and remained unrecognised. Some of the polluting chemicals are known to be immunological adjuvants.

GEORGE HEARN

City Hospital Trust,

Birmingham B187QH

Honorary consultant physician

JONATHAN MABERLY Consultant phygician HONOR ANTHONY Clinical assistant

Airedale General Hospital

Steeton,

Keighley BD20 6TD

1 Ferguson A. Ulcerative colitis and Crohn's disease. BMf 1994; 309:355-6. (6 August.)

2 Alun-Jones VA, Hunter JO. Crohn's disease: maintenance of remission by diet. Lancet 1985;ii:177-80.

3 Riordan AM, Hunter JO, Cowan RE, Crampton JR, Davidson AR, Dickinson RJ, et al. Treatment of active Crohn's disease by exclusion diet: East Anglian multicentre controlled trial. Lancet 1993;342:1131-4.

4 McEwen LM. A double-blind controlled trial of enzyme potentiated hyposensitisation for the treatment of ulcerative potentiated hyposensitisation for the

5 Subcommittee of British Society for Allergy and Environmental Medicine and British Society for Nutritional Medicine. Effective allergy practice: a document on standards of care and management for the allergy parient. Southampton: BSAEM, BSNM, 1994.

\section{GMC reconsiders its procedures}

EDrTor,-I was concerned to read Philip Thomas's article about Dr AB, who had to retire on grounds of ill health. ${ }^{1}$ The article discusses the effect of a letter that $\mathrm{Dr} A B$ received from the General Medical Council after applying for exemption from the annual retention fee. I am sorry that the letter caused distress. The offending comments were incorporated at the suggestion of a highly experienced medical member of the council and were intended to encourage $\mathrm{Dr} A B$ to be optimistic about the possibility of a full recovery.

My colleagues strive to treat all members of the profession, but particularly those who are ill, with respect and courtesy. Good intentions seem to have gone astray on this occasion. We are looking again at our procedures-specifically, whether in these circumstances it is appropriate to convey such information in this way.

ROBERT KILPATRICK

General Medical Council,

London W1N 6AF

1 Thomas P. Who cares for those who care? BMF 1994;309:747. (17 September.)

\section{Doctors' right to refuse to perform abortions}

EDrTor,-Dolores Dooley asks why doctors are given a right to conscientious refusal to perform abortion but nurses are not given the right to refuse to assist. ${ }^{1}$ But why were doctors given an open ended right to refuse in the first place? Correctly, gynaecologists already in post and those already in training when the Abortion Act became law were given the right to refuse to perform abortions, but why did that right carry on? All those who entered training in obstetrics and gynaecology after 1967 must have known that they would be called on to perform abortions. If they felt that they could not do so they should have opted for training in another branch of medicine. Now we have the absurd situation in which newly appointed consultants can announce after their appointment that they will not perform abortions. Is there really such a thing as a right to become a gynaecologist?
Surely, doctors exist to meet the needs of patients, not the other way round.

Instead of extending this right to refuse from doctors to nurses we should be curtailing the open ended right erroneously given to doctors.

C G B SIMPSON

Bronglais General Hospital,

Consultant pathologist

\section{Aberystwyth,}

Dyfed SY23 1ER

1 Dooley D. Conscientious refusal to assist with abortion. BMF 1994;309:622-3. (10 September.)

\section{Solving the population problem}

EdrTor,-A J McMichael's editorial on the Cairo conference on population and development presents the public health imperative to reduce world population growth.' But in viewing the problem as a straightforward interaction between health and the number of people sharing a finite resource the editorial is surprisingly short of answers. Could the reason for this be that the author fails to give enough importance (surprisingly so for an epidemiologist) to the confounding effect of poverty?

At the risk of being branded heretics, we would suggest that public health is irrelevant to the debate on population. Public health in Britain was terrible in Victorian England, when the population was much smaller. In modern day India, where public health is generally bad, the better off sections of the population enjoy fairly good health. By contrast, in the United States, where public health is generally good, segments of the population are worse off than the populations in some Third World countries.

This is not to say that there isn't a population problem. There is, but it is compounded, and to an extent fuelled, by the problems of poverty and unequal distribution and consumption of resources. The conventional view of the global population problem as being entirely a problem of inexorably rising numbers of people, particularly in poor countries, leads equally inexorably to the knee jerk response of "more contraception." A week of futile discussion in Cairo centred on the attempt to get a consensus on such irrelevancies as the availability of contraception and abortion. All the evidence from research studies and past experience indicates that the most that can be expected from freely available contraceptive services is a drop in the number of unwanted pregnancies. Women find it easier to attain the so called desired family size.

The real challenge is to alter the popular perception of desired family size by raising the opportunity cost of having a baby. This calls for a mix of economic, educational, land use, and social policies, which need international agreement and support, as well as sacrifices on the part of rich countries. It may come as a surprise to those who are horrified by the prospect of billions of citizens of the Third World demanding a share of the wealth of the earth that these policies are also those that promote economic growth, reduce poverty, and lead to a more equitable distribution of wealth.

As the Economist summed it up: "Visitors to Cairo, please note: look after poverty and population will (largely) take care of itself"2; so, we might add, will public health.

VIDYA RAO

University of Nottingham

Lecturer in community child health

Nottingham NG7 2UH

JAMMI NAGARAJ RAO Public health physician

Sandwell Health Authority,

West Bromwich B71 4NA

McMichael AJ. Cairo conference. BMF 1994;309:554-5. (3 September.)

2 A populous planet [editorial]. Economist 1994 Sep 3:16. 